\title{
Calculation of the underground gas store functioning parameters in the water drive mode for maintenance of gas extraction process
}

\author{
Pyanylo Ya., Vavrychuk P. \\ Centre of Mathematical Modelling of Pidstryhach Institute \\ for Applied Problems of Mechanics and Mathematics NAS of Ukraine \\ 15 Dudayev str., 79005, Lviv, Ukraine
}

(Received 18 December 2016)

\begin{abstract}
A model problem for the gas extraction process from UGS while substituting it with water is developed. The connection between the mass flowrate and pressure values in the main gas pipeline and on the outer water surface is established. A mathematic model for calculation of the UGS functioning parameters during the period of gas extraction is constructed. The results obtained are tested on the model problem.
\end{abstract}

Keywords: underground gas store (UGS), mass flowrate, Bessel functions, gas-water contact (GWC), gas-compressor station (GCS), gas transportation system (GTS).

2000 MSC: 35B, 65P, 33C10

UDC: $5196: 539.3$

\section{Introduction}

While creating and using underground gas stores, one of the main questions is establishing of functioning parameters for the underground gas store for maintenance of gas extraction process (gas flooding) in case any water is present in formations. Presence of water is detected almost in all gas stores (deposits) created in the depleted fields. Notwithstanding the great amount of the researches, currently no sufficient theory for describing of processes taking place in formations - collectors of gas stores with edge water has been yet proposed. Calculating UGS functioning parameters is getting complicated also due to the uncertainty of the porous medium parameters and its non-homogeneousness. This demands building of the corresponding adaptation models and methods, which allow specification of model parameters in accordance with the measured parameters (pressure, discharge, etc.).

Aim of work is to build a model and study the process of gas extraction from UGS, with the water presence in the formation, and calculation of underground gas store functioning parameters for maintenance of the given process.

\section{Mathematic models describing gas flow during the UGS operation period}

Distribution of the formation pressure near the well is described by the formula [1-3]

$$
p_{p l}^{2}-p_{c}^{2}=2 D F G
$$

where

$$
D(r, \tau)=\frac{\left(b \lambda_{m}\right) Z_{1}\left(b \lambda_{m}\right) Z_{0}\left(r \lambda_{m}\right)}{\left(a \lambda_{m}\right)^{2} Z_{0}^{2}\left(a \lambda_{m}\right)-\left(b \lambda_{m}\right)^{2} Z_{1}^{2}\left(b \lambda_{m}\right)}
$$

and

$$
\frac{1}{F}=\frac{4 \pi n k h g}{\beta(n+1) \mu} \sum_{m=1}^{\infty} \frac{\left(b \lambda_{m}\right)^{2} Z_{1}\left(b \lambda_{m}\right) Z_{1}\left(r \lambda_{m}\right) \exp \left(-\frac{p_{0} \tau \lambda_{m}^{2}}{D}\right)}{\left(a \lambda_{m}\right)^{2} Z_{0}^{2}\left(a \lambda_{m}\right)-\left(b \lambda_{m}\right)^{2} Z_{1}^{2}\left(b \lambda_{m}\right)}
$$


Connection of the formation pressure with the bottom-hole pressure $[1,3]$

$$
p_{p l}^{2}-p_{b}^{2}=A q+B q^{2} .
$$

Here

$$
A=\frac{A_{1}}{k_{p l}}+\frac{A_{2}}{k_{b}}, \quad B=\frac{B_{1}}{k_{p l}^{3 / 2}}+\frac{B_{2}}{k_{b}^{3 / 2}} .
$$

In order to calculate pressure distribution in flowlines and horizontal pipelines it is enough to use the stationary models of the gas flow:

In the working string

$$
p(x)=\sqrt{p_{0}^{2} e^{-b}-\lambda z \frac{R T}{D}\left(\frac{M}{S}\right)^{2} \frac{1-e^{-b}}{b} x},
$$

and horizontal pipeline (flowline) [1-3]

$$
p(x)=\sqrt{p_{0}^{2}-\lambda z \frac{g R T}{D}\left(\frac{M}{S}\right)^{2} x},
$$

marked here:

$$
S=\frac{\pi D^{2}}{4}, \quad b=\frac{2 g \Delta h}{z R T} .
$$

Gas compression coefficient may be calculated according to formula

$$
z=\frac{1}{1+f p}
$$

where $f=\left(24-0.21 t^{\circ} \mathrm{C}\right) \cdot 10^{-4}$, and $p(x)$ is measured in atmospheres. In order to calculate parameters of hookups and local resistances the empiric formula is being used [3]

$$
\Delta p=p_{g}-p_{o}=\frac{\xi}{2} \rho v^{2},
$$

which can be narrowed down to

$$
p_{g}^{2}-p_{o}^{2}=\xi \frac{z R T}{s^{2}} q^{2},
$$

where $q$ is mass flowrate. Here $v$ is speed of the gas flow, $\xi$ is coefficient depending on the local resistance type. On the basis of the last formula and measured data, empiric formulas are being built for the hookup, namely one of such dependencies may be the following:

$$
\xi=\left\{\begin{array}{l}
201.87+18455 e^{-3.1455 q}, q \leqslant 1.46 \\
1011.8-540.71 q+78.039 q^{2}, q \geqslant 1.46
\end{array}\right.
$$

Gas flow through the constriction device. Constriction devices take an important place in the GTS structure - valves, diaphragms, etc. Mass gas flowrate $\omega$, going through the constriction with the square $S$ is defined in the following way

$$
\omega=k_{q} S \sqrt{2 \frac{k}{k-1} p_{z 1} \rho_{z 1}\left[\left(\frac{p_{z 2}}{p_{z 1}}\right)^{\frac{2}{k}}-\left(\frac{p_{z 2}}{p_{z 1}}\right)^{\frac{k+1}{k}}\right]},
$$

where $k_{q}$ is coefficient considering multiple factors influence and empiric formula for its calculation is known, $k$ is adiabatic exponent, $p_{z 1}, \rho_{z 1}$ are gas pressure and density to the right, and $p_{z 2}$ is pressure to the left from the constriction device. Here $p_{z 2} / p_{z 1} \leqslant 1$. 
As $p_{z 2} / p_{z 1} \leqslant 1$, thus from (8) we receive the equality

$$
\omega^{2}=2 k_{q}^{2} S^{2} \frac{k}{k-1} p_{z 1} \rho_{z 1}\left[\left(\frac{p_{z 2}}{p_{z 1}}\right)^{\frac{2}{k}}-\left(\frac{p_{z 2}}{p_{z 1}}\right)^{\frac{k+1}{k}}\right], \quad p=\rho z R T .
$$

The last equality may be narrowed down to

$$
\left(1-\frac{p_{z 1}-p_{z 2}}{p_{z 1}}\right)^{\frac{2}{k}}-\left(1-\frac{p_{z 1}-p_{z 2}}{p_{z 1}}\right)^{\frac{k+1}{k}}=\frac{\omega^{2}(k-1)}{2 k_{q} S p_{z 1} \rho_{z 1} k},
$$

or, considering inequality $\left(p_{z 1}-p_{z 2}\right) / p_{z 1}<1$,

$$
\left(\frac{k+1}{k}-\frac{2}{k}\right) \frac{p_{z 1}-p_{z 2}}{p_{z 1}}=\frac{\omega^{2}(k-1)}{2 k_{q}^{2} S^{2} p_{z 1} \rho_{z 1} k} .
$$

Thus

$$
p_{z 1}-p_{z 2}=\frac{\omega^{2}(k-1)}{2(k-1) k_{q}^{2} S^{2} \rho_{z 1}} .
$$

If using approximate relationship

$$
\frac{1}{\rho_{z 1}}=\frac{z R T}{p_{z 1}}=\frac{2 z R T}{p_{z 1}+p_{z 2}}
$$

one will receive

$$
\begin{gathered}
p_{z 1}^{2}-p_{z 2}^{2}=q^{2} \frac{z R T \omega^{2}(k-1)}{q^{2}(k-1) k_{q}^{2} S^{2}}=a_{z z} q^{2}, \\
a_{z z}=\frac{z R T \omega^{2}(k-1)}{q^{2}(k-1) k_{q}^{2} S^{2}} .
\end{gathered}
$$

Work of the compression station is characterized by the compression coefficient $\varepsilon$. In such a case, if $p_{k 2}$ is gas pressure after exit from GCS, then $p_{k 2}=\varepsilon p_{z 2}$, or $p_{k 2}^{2}=\varepsilon^{2} p_{z 2}^{2}$.

Using formulas (1)-(10), necessary to build gas-dynamic control of the system formation UGS main gas pipelines, we will receive the following equation to define mass flowrate $q$ :

$$
p_{p l}^{2}-\varepsilon^{-2} p_{k 2}^{2} e^{b}=q\left(A+\frac{2}{q} D F G\right)+q^{2}\left(B+a_{r}+\xi \frac{z R T}{s^{2}}+a_{s}+a_{z z}\right) e^{b}
$$

\section{Definition of water pressure on the inner contour.}

Formation of the underground store with presence of water and gas will be modelled with the enclosed porous cylindrical fields with the common axis. In case the porousness and penetrating of the cylindrical environments containing water as well as mass flowrate are known, then, within the process of gas extraction the effective porous volume to be taken by water will be increased by that flowrate (Fig. 1).

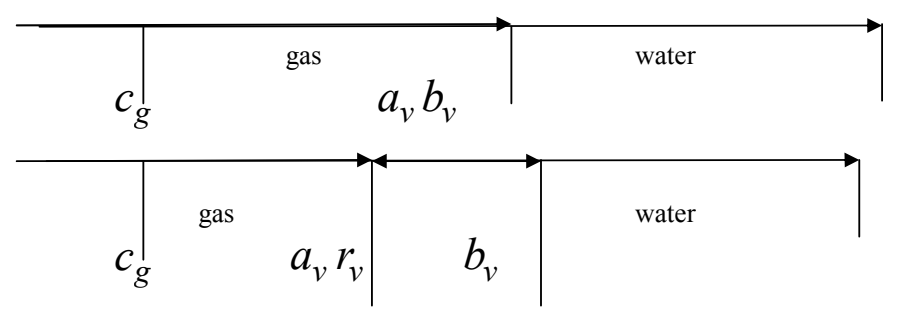

Fig. 1. Scheme of gas-water edge substitution within the process of gas extraction. 
At the start time effective porous volume $\Omega_{1 v}$ containing the same water volume

$$
\Omega_{1 v}=\pi h m_{v}\left(b_{v}^{2}-a_{v}^{2}\right) .
$$

if $q$ is mass flowrate, then the water inflow is increased by the same value. Thus the inner radius of the water cylinder decreases by the certain value $r_{v}$. Due to movements of the lower edge the quantity of water will be

$$
\Omega_{1 v}+q=\pi h m_{v}\left(b_{v}^{2}-\left(a_{v}-r_{v}\right)^{2}\right) .
$$

Using the formula (12) one can find how the inner radius decreases during the time unit

$$
r_{v}=a_{v}-\sqrt{b_{v}^{2}-\frac{\Omega_{1 v}+q}{\pi h m_{v}}}
$$

As the last formula defines the radius change during the time unit, it appears to be nothing less than the mean speed of the water contour movement, namely

$$
v_{v}=a_{v}-\sqrt{b_{v}^{2}-\frac{\Omega_{1 v}+q}{\pi h m_{v}}}
$$

Taking into account that

$$
v=-\frac{k}{\mu} \frac{\partial p}{\partial r}
$$

then

$$
d p=-\frac{\mu}{k} v d r=-\frac{\mu}{k}\left(a_{v}-\sqrt{b_{v}^{2}-\frac{\Omega_{1 v}+q_{v}}{\pi h m_{v}}}\right) d r
$$

In case all parameters remain constant, them from the last formula for GWC radius change by $r$ it is necessary to execute the equality

$$
p_{1}-p_{0}=\frac{\mu}{k} v r=-\frac{\mu}{k}\left(a_{v}-\sqrt{b_{v}^{2}-\frac{\Omega_{1 v}+q}{\pi h m_{v}}}\right) r .
$$

Here $p_{0}$ is the start value of the pressure on the surface of the inner cylinder for water, and $p_{1}$ is value of pressure on the surface of the inner cylinder for water while volume change on the mass flowrate. Formula (13) marks pressure fall on the surface of the inner cylinder per time unit. Therefore, from the balanced correlations the inner edge condition for the moving water will be

$$
p_{1}=p_{0}-\frac{\mu}{k} v r=p_{0}-\frac{\mu}{k}\left(a_{v}-\sqrt{b_{v}^{2}-\frac{\Omega_{1 v}+q}{\pi h m_{v}}}\right) r .
$$

If $t_{v}$ is time, during which the gas extraction takes place, then the formula (14) will look like

$$
p_{1 v}=p_{0}-\frac{\mu}{k}\left(a_{v}-\sqrt{b_{v}^{2}-\frac{\Omega_{1 v}+t_{v} q}{\pi h m_{v}}}\right) r_{v} .
$$

\section{Definition of gas pressure on the inner contour}

Let us perform the same balance procedure for gas. At the start time the effective porous volume in the gas area is $\Omega_{g}$. Then

$$
\Omega_{g}=\pi h m_{g}\left(a_{g}^{2}-c_{g}^{2}\right)
$$


Per time unit the volume will decrease by flowrate $q$. Outer gas radius will decrease by value $r_{v}$, thus

$$
\Omega_{g}-q=\pi h m_{g}\left(\left(a_{g}-r_{v}\right)^{2}-c_{g}^{2}\right) .
$$

In such a case only the upper edge will be taken into account. From the formula (16) one can find how the outer radius will decrease per time unit

$$
r_{v}=a_{g}-\sqrt{\frac{\Omega_{g}-q}{\pi h m}+c_{g}^{2}}
$$

The last formula is nothing less than the movement of the inner water edge. As far as

$$
G=\gamma v=-\frac{k}{2 \mu \beta} \frac{\partial p}{\partial x}
$$

then

$$
d p=-\frac{2 \mu \beta \gamma}{k} v d r=-\frac{2 \mu \beta \gamma}{k}\left(a_{g}-\sqrt{\frac{\Omega_{1}-q}{\pi h m}+c_{g}^{2}}\right) d r .
$$

As all parameters are considered to be constant, then from the last formula

$$
p_{1}-p_{0}=\frac{2 \mu \beta \gamma}{k} v r=-\frac{2 \mu \beta \gamma}{k}\left(a_{g}-\sqrt{\frac{\Omega_{1}-q}{\pi h m}+c_{g}^{2}}\right) r .
$$

Here $p_{0}$ is the start pressure value on the surface of the inner cylinder for water. The last formula defines the pressure fall on the surface of the inner cylinder for water per time unit. Having assumed that $t_{v}$ is time, during which the gas extraction takes place, we will receive the edge condition for the gas flow in the following way

$$
p_{1}=p_{0}-\frac{2 \mu \beta \gamma}{k} v r=p_{0}-\frac{2 \mu \beta \gamma}{k}\left(a_{g}-\sqrt{\frac{\Omega_{1}-t_{v} q}{\pi h m}+c_{g}^{2}}\right) r .
$$

It is clear that on the GWC edge there should not be any breaks for speed field, namely the speed of the gas drainage should be equal to the speed on water inflow, and correspondingly, the pressure values calculated in accordance with the formulas (15) and (17) should coincide.

\section{Definition of water pressure on the outer contour.}

Let us assume that on surface $r_{1}=a$ there is water pressure $P_{1}$, and on surface $r_{2}=b$ there is pressure $P_{2}$, while the initial distribution is provided in formula $f(r)$. In this case, the solution of the original problem of mathematical physics is presented in the following form: $P=P_{s}+P_{n}$, where

$$
P_{s}=\frac{P_{1} \ln (b / r)+P_{2} \ln (r / a)}{\ln b / a}
$$

determines the steady pressure distribution among the surfaces, and the second solution component is as follows:

$$
\begin{aligned}
P_{n}= & \frac{\pi^{2}}{2} \sum_{n=1}^{\infty} \frac{\alpha_{n}^{2} J_{0}^{2}\left(a \alpha_{n}\right)}{J_{0}^{2}\left(a \alpha_{n}\right)-J_{0}^{2}\left(b \alpha_{n}\right)} \exp \left(-\kappa \alpha_{n}^{2} \tau\right) U_{0}\left(r \alpha_{n}\right) \int_{a}^{b} r f(r) U_{0}\left(r \alpha_{n}\right) d r \\
& -\pi \sum_{n=1}^{\infty} \frac{\left[P_{2} J_{0}\left(a \alpha_{n}\right)-P_{1} J_{0}\left(b \alpha_{n}\right)\right] J_{0}\left(a \alpha_{n}\right) U_{0}\left(r \alpha_{n}\right)}{J_{0}^{2}\left(a \alpha_{n}\right)-J_{0}^{2}\left(b \alpha_{n}\right)} \exp \left(-\kappa \alpha_{n}^{2} \tau\right)
\end{aligned}
$$

Mathematical Modeling and Computing, Vol.3, No. 2, pp. 208-216 (2016) 
Here $U_{0}(a r)=J_{0}(a r) Y_{0}(a b)+J_{0}(a b) Y_{0}(a r), J_{i}(x)$ and $Y_{i}(x)$ are first and second kind Bessel functions of actual argument of order $i$ respectively.

Then

$$
\begin{aligned}
\frac{\partial P_{n}}{\partial r}= & \frac{\pi^{2}}{2} \sum_{n=1}^{\infty} \frac{\alpha_{n}^{2} J_{0}^{2}\left(a \alpha_{n}\right)}{J_{0}^{2}\left(a \alpha_{n}\right)-J_{0}^{2}\left(b \alpha_{n}\right)} \exp \left(-\kappa \alpha_{n}^{2} \tau\right) U_{1}\left(r \alpha_{n}\right) \int_{a}^{b} x f(x) U_{0}\left(x \alpha_{n}\right) d x \\
& -\pi \sum_{n=1}^{\infty} \frac{\left[P_{2} J_{0}\left(a \alpha_{n}\right)-P_{1} J_{0}\left(b \alpha_{n}\right)\right] J_{0}\left(a \alpha_{n}\right) U_{1}\left(r \alpha_{n}\right)}{J_{0}^{2}\left(a \alpha_{n}\right)-J_{0}^{2}\left(b \alpha_{n}\right)} \exp \left(-\kappa \alpha_{n}^{2} \tau\right)
\end{aligned}
$$

where $U_{1}\left(r \alpha_{n}\right)=-\alpha_{n}\left[J_{1}\left(\alpha_{n} r\right) Y_{0}(a b)+J_{0}(a b) Y_{1}\left(\alpha_{n} r\right)\right], \alpha_{n}$ stand for roots of nonlinear equations

$$
J_{0}(\alpha a) Y_{0}(\alpha b)-J_{0}(\alpha b) Y_{0}(\alpha a)=0 .
$$

Since

$$
v=-\frac{k}{\mu} \frac{\partial p}{\partial y}, \quad q=v S=2 \pi r S v, \quad v=\frac{q}{2 \pi r S}, \quad \frac{q}{2 \pi r S}=-\frac{k}{\mu} \frac{\partial p}{\partial r}, \quad q=-2 \pi r S \frac{k}{\mu} \frac{\partial p}{\partial r} .
$$

Then we get the following equation

$$
\begin{aligned}
\frac{q}{2 \pi r S}= & \left\{\frac{P_{2}-P_{1}}{\ln (b / a)}+r \frac{\pi^{2}}{2} \sum_{n=1}^{\infty} \frac{\alpha_{n}^{2} J_{0}^{2}\left(a \alpha_{n}\right)}{J_{0}^{2}\left(a \alpha_{n}\right)-J_{0}^{2}\left(b \alpha_{n}\right)} \exp \left(-\kappa \alpha_{n}^{2} \tau\right) U_{1}\left(r \alpha_{n}\right) \int_{a}^{b} x f(x) U_{0}\left(x \alpha_{n}\right) d x\right. \\
& \left.-r \pi \sum_{n=1}^{\infty} \frac{\left[P_{2} J_{0}\left(a \alpha_{n}\right)-P_{1} J_{0}\left(b \alpha_{n}\right)\right] J_{0}\left(a \alpha_{n}\right) U_{1}\left(r \alpha_{n}\right)}{J_{0}^{2}\left(a \alpha_{n}\right)-J_{0}^{2}\left(b \alpha_{n}\right)} \exp \left(-\kappa \alpha_{n}^{2} \tau\right)\right\} \frac{k}{\mu} .
\end{aligned}
$$

Here $\kappa=\frac{\alpha k}{m \mu}$, where $\alpha$ is surround module of tension, $k$ is permeability of environment, $\mu$ is dynamic viscosity of gas, $m$ is porosity of reservoir.

Initial pressure distribution set the following formula $f(r)=\frac{P_{1} \ln (b / r)+P_{2} \ln (r / a)}{\ln (b / a)}$, then

$$
\begin{array}{rl}
\int_{a}^{b} & x \frac{P_{1} \ln (b / x)+P_{2} \ln (x / a)}{\ln (b / a)} U_{0}\left(x \alpha_{n}\right) d x \\
& =\frac{1}{\ln (b / a)} \int_{a}^{b} x\left[P_{1} \ln b-P_{1} \ln x+P_{2} \ln x-P_{2} \ln a\right] U_{0}\left(x \alpha_{n}\right) d x \\
& =\frac{1}{\ln (b / a)} \int_{a}^{b} x\left[P_{1} \ln b-P_{2} \ln a+\left(P_{2}-P_{1}\right) \ln x\right] U_{0}\left(x \alpha_{n}\right) d x \\
& =\frac{1}{\ln (b / a)}\left[\left(P_{1} \ln b-P_{2} \ln a\right) \int_{a}^{b} x U_{0}\left(x \alpha_{n}\right) d x\right]+\left(P_{2}-P_{1}\right) \int_{a}^{b} x \ln x U_{0}\left(x \alpha_{n}\right) d x .
\end{array}
$$

Using an analytical representation of these integrals [4]:

$$
\int_{a}^{b} x U_{0}\left(x \alpha_{n}\right) d x=\frac{2\left[J_{0}\left(a \alpha_{n}\right)-J_{0}\left(b \alpha_{n}\right)\right]}{\pi \alpha_{n}^{2} J_{0}\left(a \alpha_{n}\right)}
$$




$$
\int_{a}^{b} x U_{0}\left(x \alpha_{n}\right) \ln x d x=\frac{2\left[J_{0}\left(a \alpha_{n}\right) \ln b-J_{0}\left(b \alpha_{n}\right) \ln a\right]}{\pi \alpha_{n}^{2} J_{0}\left(a \alpha_{n}\right)}
$$

we get that the equation (20) takes the following form

$$
\begin{array}{rl}
\int_{a}^{b} & x \frac{P_{1} \ln (b / x)+P_{2} \ln (x / a)}{\ln (b / a)} U_{0}\left(x \alpha_{n}\right) d x= \\
\quad= & \frac{1}{\ln (b / a)}\left[\left(P_{1} \ln b-P_{2} \ln a\right) \frac{2\left[J_{0}\left(a \alpha_{n}\right)-J_{0}\left(b \alpha_{n}\right)\right]}{\pi \alpha_{n}^{2} J_{0}\left(a \alpha_{n}\right)}+\left(P_{2}-P_{1}\right) \frac{2\left[J_{0}\left(a \alpha_{n}\right) \ln b-J_{0}\left(b \alpha_{n}\right) \ln a\right]}{\pi \alpha_{n}^{2} J_{0}\left(a \alpha_{n}\right)} .\right]
\end{array}
$$

Grouping separate terms which include $P_{1}$ and $P_{2}$ then the last formula can be rewritten as:

$$
\int_{a}^{b} x \frac{P_{1} \ln (b / x)+P_{2} \ln (x / a)}{\ln (b / a)} U_{0}\left(x \alpha_{n}\right) d x=\frac{2(\ln a-\ln b)}{\pi \alpha_{n}^{2} \ln (b / a)}\left[P_{1} \frac{J_{0}\left(b \alpha_{n}\right)}{J_{0}\left(a \alpha_{n}\right)}-P_{2}\right] .
$$

Let

$$
U_{2}\left(r, \alpha_{n}, \kappa, \tau\right)=\exp \left(-\kappa \alpha_{n}^{2} \tau\right) U_{1}\left(r \alpha_{n}\right)
$$

Then the equation (19) written as

$$
\begin{aligned}
\frac{q \mu}{2 \pi r k S}= & \frac{P_{2}-P_{1}}{\ln (b / a)}+r \frac{\pi^{2}}{2} \sum_{n=1}^{\infty} \frac{\alpha_{n}^{2} J_{0}^{2}\left(a \alpha_{n}\right)}{J_{0}^{2}\left(a \alpha_{n}\right)-J_{0}^{2}\left(b \alpha_{n}\right)} U_{2}\left(r, \alpha_{n}, \kappa, \tau\right) \frac{2(\ln a-\ln b)}{\pi \alpha_{n}^{2} \ln (b / a)}\left[P_{1} \frac{J_{0}\left(b \alpha_{n}\right)}{J_{0}\left(a \alpha_{n}\right)}-P_{2}\right] \\
& -r \pi \sum_{n=1}^{\infty} \frac{\left[P_{2} J_{0}\left(a \alpha_{n}\right)-P_{1} J_{0}\left(b \alpha_{n}\right)\right] J_{0}\left(a \alpha_{n}\right)}{J_{0}^{2}\left(a \alpha_{n}\right)-J_{0}^{2}\left(b \alpha_{n}\right)} U_{2}\left(r, \alpha_{n}, \kappa, \tau\right) .
\end{aligned}
$$

We introduce the notation

$$
\begin{aligned}
& F_{2}\left(a, b, r, \alpha_{n}, \kappa, \tau\right)=\frac{1}{\ln (b / a)}-r \pi \sum_{n=1}^{\infty} \frac{2 \frac{(\ln a-\ln b)}{\ln (b / a)} J_{0}^{2}\left(a \alpha_{n}\right)}{J_{0}^{2}\left(a \alpha_{n}\right)-J_{0}^{2}\left(b \alpha_{n}\right)} U_{2}\left(r, \alpha_{n}, \kappa, \tau\right) \\
& F_{1}\left(a, b, r, \alpha_{n}, \kappa, \tau\right)=-\frac{1}{\ln (b / a)}+r \pi\left(\frac{(\ln a-\ln b)}{\ln (b / a)}+1\right) \sum_{n=1}^{\infty} \frac{J_{0}\left(a \alpha_{n}\right) J_{0}\left(b \alpha_{n}\right)}{J_{0}^{2}\left(a \alpha_{n}\right)-J_{0}^{2}\left(b \alpha_{n}\right)} U_{2}\left(r, \alpha_{n}, \kappa, \tau\right) .
\end{aligned}
$$

Then the equation (20) takes the form

$$
\frac{q \mu}{2 \pi r k S}=P_{2} F_{2}\left(a, b, r, \alpha_{n}, \kappa, \tau\right)+P_{1} F_{1}\left(a, b, r, \alpha_{n}, \kappa, \tau\right) .
$$

Thence

$$
P_{2}=\frac{\frac{q \mu}{2 \pi r k S}-P_{1} F_{1}}{F_{2}}
$$

If $\tau \rightarrow \infty$, or sufficiently large then

$$
F_{2}=\frac{1}{\ln (b / a)}, \quad F_{1}=-\frac{1}{\ln (b / a)} .
$$

Then

$$
P_{2}=P_{1}+\ln (b / a) \frac{q \mu}{2 \pi r k S}
$$




\section{Computational experiment}

Testing of the results conducted in the computational experiment the following input parameter values: $p_{0}=70 \cdot 98066.5\left(\mathrm{~N} / \mathrm{m}^{2}\right) ; p_{g z p}=50 \cdot 98066.5\left(\mathrm{~N} / \mathrm{m}^{2}\right) ; z=0.9 ; R=8.3144621(\mathrm{~J} /(\mathrm{mol} \cdot \mathrm{K})) ; T=$ $293(\mathrm{~K}) ; \rho_{0}=0.68\left(\mathrm{~kg} / \mathrm{m}^{3}\right) ; \mu=0.0008\left(\mathrm{~m}^{2} / \mathrm{s}\right) ; g=9.8\left(\mathrm{~m} / \mathrm{s}^{2}\right) ; \alpha=0.8 ; m=0.28 ; k=4 \cdot 10^{-15}$; $\rho=998\left(\mathrm{~kg} / \mathrm{m}^{3}\right)$.

Table 1. The value of pressure in the control points by changing the amount of available gas in UGS $(a(\mathrm{~m})$ is the radius of the inner contour(the border "gas-water"), $b(\mathrm{~m})$ is the radius of the outer contour of water, $P_{1}$ (ata) is the pressure on the inner contour, $P_{2}$ (ata) is the pressure on the outer contour, $h(\mathrm{~m})$ is the height of the column of water to maintain pressure on the outer contour of water).

Table 2. The distribution of pressure on the outer contour of water depending on the time $(t(\mathrm{~s})$ is time, $P_{1}$ (ata) is the pressure on the inner contour, $P_{2}$ (ata) is the pressure on the outer contour).

\begin{tabular}{|c|c|c|c|c|}
\hline$a$ & $b-a$ & $P_{1}$ & $P_{2}$ & $h$ \\
\hline 500 & 500 & 56.29 & 59.24 & 592.8 \\
\hline 400 & 600 & 54.97 & 61.43 & 614.7 \\
\hline 300 & 700 & 54.12 & 62.87 & 629.1 \\
\hline 200 & 800 & 53.87 & 63.85 & 638.9 \\
\hline 100 & 900 & 52.18 & 66.91 & 669.6 \\
\hline 50 & 950 & 51.36 & 69.16 & 692.06 \\
\hline
\end{tabular}

\begin{tabular}{|c|c|c|}
\hline$t$ & $P_{1}$ & $P_{2}$ \\
\hline 1000 & 56.29 & 59.24 \\
\hline 5000 & 55.17 & 60.23 \\
\hline 10000 & 54.24 & 62.47 \\
\hline 50000 & 54.17 & 63.05 \\
\hline 100000 & 54.17 & 63.05 \\
\hline
\end{tabular}

\section{Conclusions}

The current work researches the process of gas extraction from UGS, in case the water is present in the formation. Mathematical model of such a process is being built. Functional connection between the mass flowrate and pressure values in the main gas pipeline and on the outer water edge is being established. Formulas for calculating of the main UGS functioning parameters during the process of gas extraction are obtained. Model problem and formulas for calculating underground gas store parameters are tested during multiple experiments.

[1] Prytula N. M., Pyanylo J. D., Prytula M. G. Undeground gas storage (mathematical models and methods). Lviv, RASTR-7 (2015), p. 266.

[2] Pyanylo J.D., VavrychukP.H. Calculation of the gas-water boundary speed during operation of underground gas storage. Physico-mathematical modelling and informational technologies, no. 18, 165-172 (2013).

[3] Vecherik R.L., Pyanylo J.D., Prytula M.H., Hayetskyy J.B. Mathematical modeling of gas flow in the system reservoir of underground gas storage-main pipeline. Oil and gas, no. 6, 83-89 (2014).

[4] Carslaw H. S., Jaeger J. S. Conduction of heat in solids. Oxford University Press, Amen House, London E.C.4. (1959), p. 509. 


\title{
Розрахунок параметрів роботи ПСГ для підтримування процесу відбирання газу
}

\author{
П'янило Я., Вавричук П.
}

Центр математичного моделювання Інституту прикладних проблем механіки $і$ математики ім. Я. С. Підстригача НАН України

вул. Д. Дудаєва, 15, 79005, Лъвів, Украӥна

Розроблено модельну задачу процесу відбирання газу з ПСГ витісненням його водою. Побудовано зв'язок між дебітом свердловини та значеннями тисків у магістральному газопроводі та на зовнішній межі води. Наведено формули розрахунку параметрів роботи ПСГ під час відбирання газу. Отримані результати апробовано на модельній задачі.

Ключові слова: підземне сховище газу (ПСГ), дебіт свердловини, функиї Бесселя, газо-водяний контакт (ГВК), компресорна станція (KC), газотранспортна система (ГTC).

2000 MSC: 35B, 65P, 33C10

УдК: $5196: 539.3$ 